\title{
Arteria trigemina primitiva - radiological report of three cases and review of literature
}

\author{
A. Tomalczyk ${ }^{1}$, Z. Kaurzel ${ }^{1}$, W. Szubert ${ }^{1}$, P. Oszukowski ${ }^{2}$ \\ ${ }^{1}$ Department of Radiology, Copernicus Memorial Hospital, Lodz, Poland \\ 2Department of Clinical Morphology in the Chair of Anatomy, Medical University of Lodz, Poland
}

[Received: 26 March 2017; Accepted: 19 May 2017]

\begin{abstract}
The main aim of this paper is to present 3 cases of persistent (patent) primitive trigeminal artery incidentally revealed during various radiological examinations. The presence and function of these vessels in extrauterine life is sometimes associated with other vascular abnormalities, e.g. aneurysms, haemangiomas, moyamoya disease, but frequently found incidentally without any negative signs or symptoms. The presented cases of patients with primitive trigeminal artery clearly show that the reported ailments, which had made the diagnostic imagining necessary, were not associated with the patency of this artery. (Folia Morphol 2017; 76, 4: 757-761)
\end{abstract}

Key words: primitive carotid-basilar anastomosis, primitive trigeminal artery, anatomic variations, incidence

\section{INTRODUCTION}

The blood supply of the human brain stems from four main arteries: left and right internal carotid arteries, which originate from the bifurcation of the common carotid arteries, and two vertebral arteries (left and right), which are branches of the subclavian arteries. After entering the skull they form a more or less regular vascular circle around the diencephalon, also referred to as the circle of Willis (Fig. 1). After passing through the carotid canal and cavernous sinus, each of the internal carotid arteries (ICA) ends with a bifurcation into the middle cerebral artery (MCA) (larger in diameter) and the anterior cerebral artery (ACA) (smaller in diameter). Before entering longitudinal cerebral fissure both anterior cerebral arteries are connected with each other by a single vascular anastomosis known as anterior communicating artery (ACOA). This junction divides anterior cerebral artery into two parts: pre- (A1) and postanastomosing (A2). The vertebral arteries (VA) after passing through the foramen magnum ascend in the posterior skull fossa and feed into a single artery called the basilar artery (BA). After giving off branches that mainly supply the brain stem, BA ends with a bifurcation into the symmetric posterior cerebral arteries (PCA). The junction between each of the latter with ipsilateral ICA is called the posterior communicating artery (ACoP) and similar to ACoA it divides PCA into two parts: pre- $(P 1)$ and postanastomosing $(P 2)[6,11$, 14, 16, 19, 27].

The above described scheme applies to extrauterine life and adolescence only. During the embryonic life the system of brain arteries is more complex. It is suspected that PCA are developmentally associated with ICA. At the beginning, the posterior fossa is fed by the "carotid-basilar anastomosis" and by the caudal division of the ICA which is the ACoP and the future P1 that connects with the ipsilateral longitudinal neural artery. A caudal branch of ICA gives rise to the posterior choroidal, diencephalic and mesencephalis arteries. As this branch reaches caudally, communication is made with the developing longitudinal neural arteries, which initially are fed primarily by the trigeminal artery connections to the ICA's but also by the primitive otic, hypoglossal and pro-atlantal intersegmental arteries. The fusion of the 


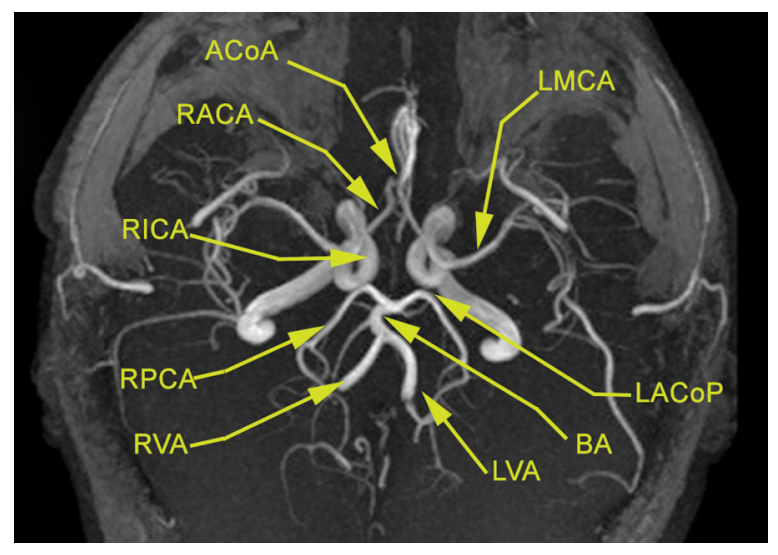

Figure 1. Magnetic resonance imaging-angiography of the most frequent variation of circle of Willis; $\mathrm{ACo}$ - anterior communicating artery; RACA — right anterior cerebral artery; RICA — right internal carotid artery; RPCA — right posterior cerebral artery; RVA — right vertebral artery; LVA — left vertebral artery; LMCA — left middle cerebral artery; LACoP — left posterior communicating artery; BA — basilar artery. Gadovist.

two longitudinal neural arteries is depending on the trigeminal regression: if the trigeminal arteries regress, the basilar trunk is made and connects the VA followed by an arterial flow reversal in the basilar trunk. If the fusion doesn't occur, the ICA system remains dominant; the basilar trunk doesn't totally develop with possibilities of persistence of the two longitudinal neural arteries, hypoplasia of the inferior part of the $B A$, aplasia of the vertebral arteries $[10,18,20,26]$.

The above mentioned arterial anastomoses disappear during the intrauterine life. After delivery the only vessels connecting two main sources of brain blood supply are the ACoPs (left and right).

Yet, the foetal arteries do not always have to vanish $[4,7]$. The presence and function of these vessels in extrauterine life is sometimes associated with other vascular abnormalities $[1,2,5,13,15,17,23,24]$ but frequently found incidentally without any negative signs or symptoms.

The main aim of this paper is to present the cases of persistent-patent primitive trigeminal artery, which was found incidentally during radiological examinations.

\section{CASE REPORTS}

\section{Case 1}

A 67-year-old woman, with a negative past medical history, was admitted to the hospital due to the sudden acute headache with a probable loss of consciousness. No other complaints were reported. The patient's neurological examination revealed mild neck

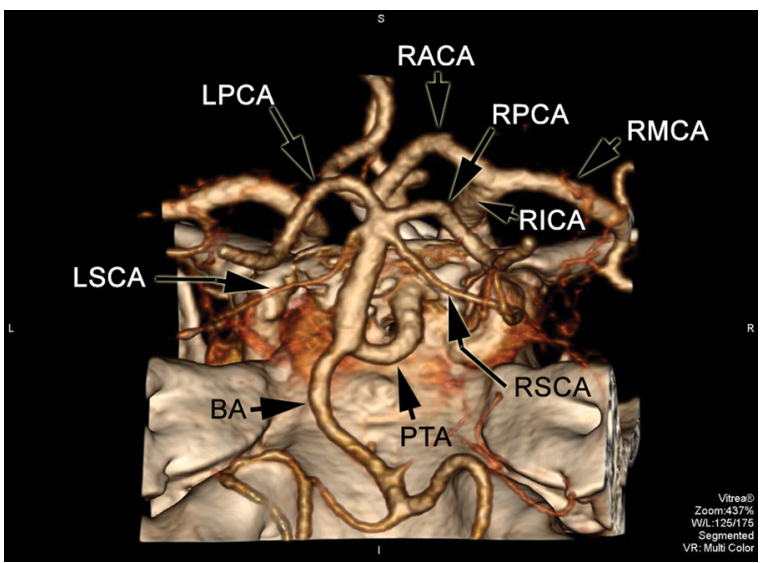

Figure 2. Three-dimensional reconstruction of computed tomography-angiography of the brain; PTA — primitive trigeminal artery; RACA — right anterior cerebral artery; LPCA — left posterior cerebral artery; RPCA — right posterior cerebral artery; RMCA right middle cerebral artery; RICA — right internal carotid artery; LSCA — left superior cerebellar artery; RSCA — right superior cerebellar artery; BA — basilar artery. Ultravist.

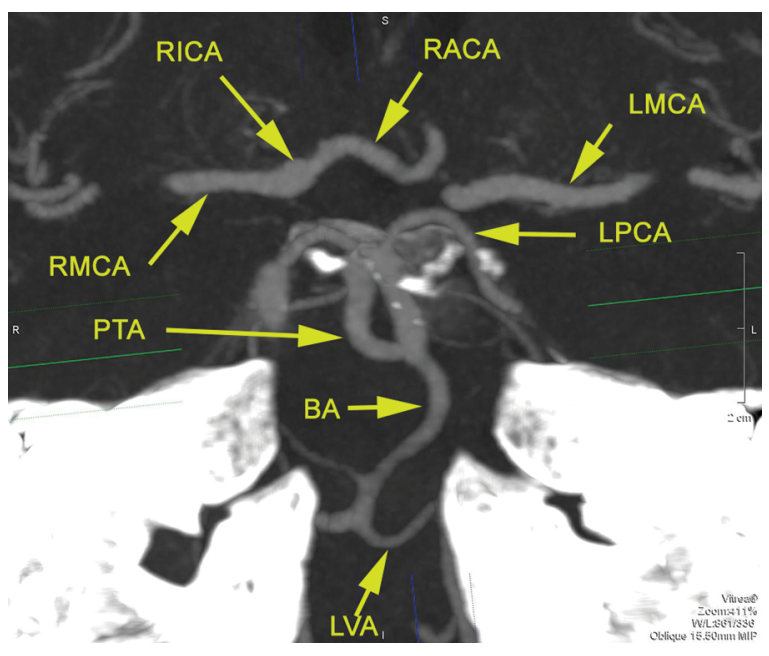

Figure 3. Computed tomography-angiography of the brain; PTA primitive trigeminal artery; RICA — right internal carotid artery; RACA — right anterior cerebral artery; RMCA — right middle cerebral artery; LMCA — left middle cerebral artery; LPCA — left posterior cerebral artery; BA — basilar artery; LVA — left vertebral artery. Ultravist.

stiffness. Computed tomography (CT) showed subarachnoidal haemorrhage, whereas $\mathrm{CT}$-angiography revealed the presence of the ACoA aneurysm. Additionally, the wide vessel (diameter approximately $3 \mathrm{~mm}$ ) connecting the cavernous segment of the right ICA and the BA was observed (Figs. 2, 3). The classical angiography and embolisation were planned. Due to wide neck of aneurysm sack and high tension in catheter-guidewire system it was impossible to perform 


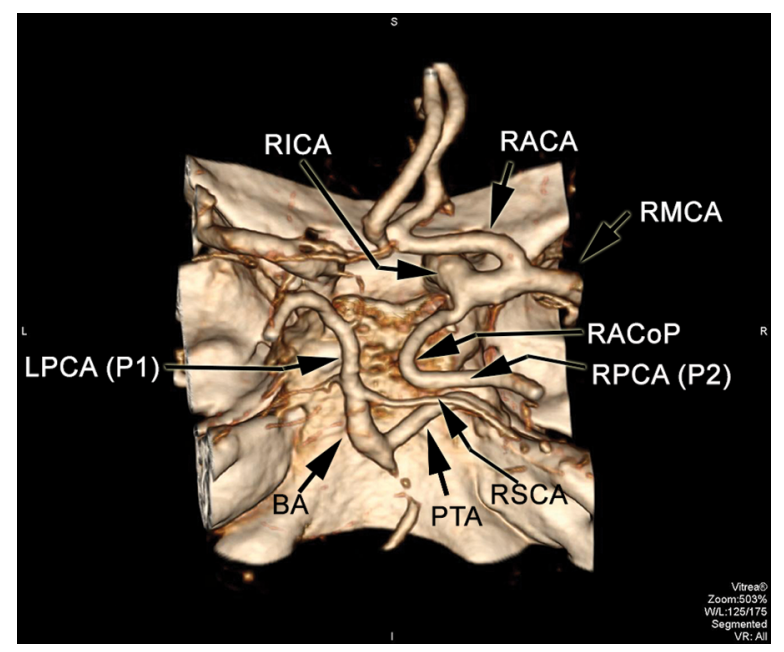

Figure 4. Three-dimensional reconstruction of computed tomography-angiography of the brain; PTA — primitive trigeminal artery; RICA - right internal carotid artery; RACA — right anterior cerebral artery; RMCA — right middle cerebral artery, RACoP — right posterior communicating artery; LPCA — left posterior cerebral artery; RPCA — right cerebral posterior artery; RSCA — right superior cerebellar artery; BA — basilar artery. Ultravist.

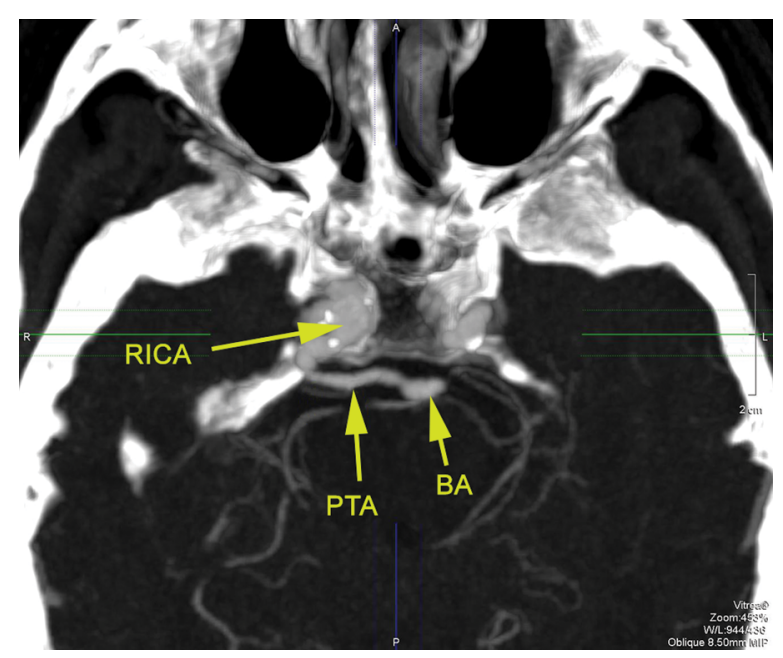

Figure 5. Computed tomography-angiography of the brain; PTA primitive trigeminal artery; RICA — right internal carotid artery; $\mathrm{BA}$ - basilar artery. Ultravist.

the embolisation and patient underwent neurosurgical treatment.

\section{Case 2}

An 82-year-old woman with a history of microangiopathic leukoencephalopathy, polyneuropathy and ischaemic heart disease underwent diagnostic procedures for chronic non-systemic balance disorders lasting for a couple of years.
The neurological examination revealed hypertonia of the lower limbs, discreet weakness of the left lower and upper limbs, dysmetria of both upper and lower limbs. The patient fell backward on Romberg's test.

The patient was referred for CT-angiography of cervical and cerebral vessels. The examination revealed critical stenosis of basilar artery localised distally to posterior inferior cerebellar artery (PICA) branches, the occlusion of the vessel could not have been ruled out. Above the stenosis a wide vessel that runs to the cavernous segment of right ICA was found, i.e. primitive trigeminal artery. Aplasia of P1 segment of right PCA and hypoplasia of $A 1$ segment of left ACA were also observed (Figs. 4, 5).

\section{Case 3}

A 45-year-old woman was admitted to the Department of Neurology for further diagnostic of the lesion localised in the left cerebral hemisphere.

The patient presented signs and symptoms of escalated right-sided hemiparesis and speech disorders which, during the neurological examination, occurred to be aggravated probably by the conversion disorder.

Contrast-enhanced magnetic resonance imaging (MRI) showed few lesions localised peripherally in the left parietal and occipital lobes, hyperintense in T2 weighted images, some of them with heterogeneous contrast enhancement. Due to various size and different localisation in comparison with previous MRI scans differential diagnosis between vascular dependent lesions and vasculitis was suggested. The patient underwent a panangiography which did not confirm vasculitis. Instead it showed wide vessel connecting the cavernous segment of right ICA with the middle section of BA (Figs. 6, 7).

\section{DISCUSSION}

The reports concerning the presence and function of patent foetal arteries are not very rare, with PTA being the most frequent carotid-basilar anastomosis discovered incidentally in adults [8]. It has been reported to become visible in $0.1 \%$ to $0.6 \%$ of all cerebral angiograms [3]. The persistence of this vessel usually leads to hypoplasia or agenesis of the ipsilateral ACoP, and leaves the ICA as the main source of blood supply to the upper brainstem region [3]. It may also be associated with the presence of hypoplastic vertebral and basilar arteries [8].

The analysis of angiographic images allowed Saltzman [22] to develop a classification based on the lo- 




Figure 6. Towne's view of a right internal carotid artery angiogram; PTA — primitive trigeminal artery; RICA — right internal carotid artery; BA — basilar artery. Ultravist.

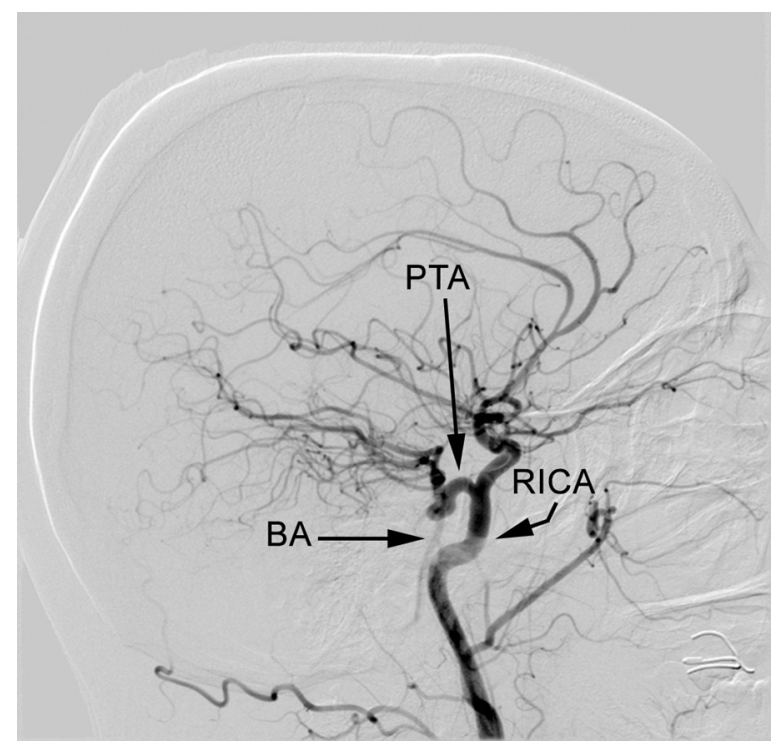

Figure 7. Lateral view of a right internal carotid artery angiogram; PTA — primitive trigeminal artery; RICA — right internal carotid artery; BA — basilar artery. Ultravist.

calisation of PCOA and the area supplied by PTA. Type I is described as PTA supplying upper BA with superior cerebellar and PCA with concomitant hypoplastic proximal BA and absent ipsilateral PCoA. Type II was defined as anterior superior cerebellar arteries being sole branches of PTA, whereas first part of PCA is absent and the remaining segments arise from ACoP. The recognition of the last type (III) is based on PTA joining the remnant of primitive paired longitudinal neural artery. Such artery does not anastomose with BA and supplies single ipsilateral cerebellar artery, most frequently anterior inferior cerebellar artery [21].

Developmental anomalies of the aortic arch vessels and PTA are repeatedly reported in the literature $[1,17]$. Despite the fact that the presence of these vessels usually does not lead to any negative outcomes, there have been reports on various disorders associated with them. Patients may present with symptoms related to hypo-perfusion of posterior circulation or microembolisation from carotid artery to posterior circulation [8]. Brockhoff and Tiwisina [5] presented a case of PTA aneurysm that had led to subarachnoidal haemorrhage. Svehla and Vitovec [25] suspected that PTA was the cause of epilepsy. Angoli [2] noticed that the patent PTA supplied the haemangioma. Stoeter and Marquardt [23] described a case of 3-year-old child whose PTA accompanied other congenital central nervous system disorders. Battista et al. [3] reported that PTA was as a cause of dizziness. Suzuki et al. [24] presented identical twin suffering from the moyamoya disease with concomitant persistent PTA variant. Komiyama et al. [13] noticed high incidence of persistent primitive arteries in moyamoya and quasi-moyamoya diseases.

The incidence of patent primitive hypoglossal artery is very low, as this artery is observed in 1-2 patients out of 2207 to 7382 undergoing diagnostic imaging procedures $[9,12]$.

\section{CONCLUSIONS}

The presented cases of patients with primitive trigeminal artery, all Saltzman type I, clearly show that the reported ailments that had made the diagnostic imagining necessary were not associated with the patency of this artery.

\section{REFERENCES}

1. Alleyne C, Krisht A, Yoo F, et al. Bilateral persistent trigeminal arteries associated with cerebral aneurysms and aortic arch vessel anomaly. Southern Med J. 1997; 90(4): 434-438, doi: 10.1097/00007611-199704000-00016.

2. Agnoli AL. [AV angiomas in persisting a. trigemina primitiva: neuroradiologico-clinical report (author's transl)]. Rontgenblatter. 1982; 35(1): 9-12, indexed in Pubmed: 7063779.

3. Battista RA, Kwartler JA, Martinez DM. Persistent trigeminal artery as a cause of dizziness. Ear Nose Throat J. 1997; 76(1): 43-45, indexed in Pubmed:9018936. 
4. Beran J, Tovarys F. [Arteria primitiva trigemina--persisting carotid-basilar anastomosis]. Cesk Radiol. 1966; 20(6): 406-410, indexed in Pubmed:5979157.

5. Brockhoff $\mathrm{V}$, Tiwisina T. [Aneurysm of the arteria primitiva trigemina persistens as a rare cause of spontaneous subarachnoid hemorrhage]. Zentralbl Neurochir. 1965; 26(6): 295-302, indexed in Pubmed: 5882670.

6. Chrzanowski R. Podstawy neuroradiologii. Wydawnictwo Lekarskie PZWL, Warszawa 1970.

7. Eadie MJ, Jamieson KG, Lennon EA. Persisting carotidbasilar anastomosis. J Neurol Sci. 1964; 1(6): 501511, doi: 10.1016/0022-510x(64)90170-4, indexed in Pubmed: 14234113.

8. Eluvathingal Muttikkal TJ, Varghese SPJ, Chavan VNK. Persistent trigeminal artery and associated vascular variations. Australas Radiol. 2007; $51 \mathrm{Spec} \mathrm{No.:} \mathrm{B31-B33,}$ doi: 10.1111/j.1440-1673.2007.01828.x, indexed in Pubmed: 17875151.

9. Fukui M, Kitamura K. Persistent primitive hypoglossal artery: A case report and review and analysis of 34 cases reported in literature. Clinical Neurol. 1969; 9: 421-28.

10. Gielecki J. Rozwój tętnic podstawy mózgowia u płodów ludzkich w oparciu o komputerową analizę obrazu. Praca habilitacyjna, Dział Wydawnictw AM w Warszawie, Warszawa 1999.

11. Gołąb B, Jędrzejewski K. Anatomia czynnościowa ośrodkowego układu nerwowego. Wydawnictwo Lekarskie PZWL, Warszawa 2000.

12. Handa J, Kikuchi H, Handa H. [Persistent carotid-basilar anastomosis; A. primitiva hypoglossica]. Fortschr Geb Rontgenstr Nuklearmed. 1967; 107(3): 421-422, doi: 10.1055/ s-0029-1228233, indexed in Pubmed: 5626378.

13. Komiyama $M$, Nakajima $H$, Nishikawa $M$, et al. High incidence of persistent primitive arteries in moyamoya and quasi-moyamoya diseases. Neurologia Medico-Chirurgica. 1999; 39(6): 416-422, doi: 10.2176/nmc.39.416.

14. Krayenbuhl H, Yaşargil MG. Die zerebrale e Angiographie. Lehrbuch fur Klinik und Praxis. Georg Thieme Verlag, Stuttgart 1965.

15. Lahl R. Carotid-basilar anastomosis (A. primitiva trigemina) in combination with abnormalities of the circulus arteriosus cerebri (Autopsy report of 4 cases). Psychiatr Neurol (Basel). 1966; 151(6): 351-65, doi: 10.1159/000127313.
16. Lasjaunias $P$, Berenstein A, Ter Brugge KG. Surgical Neuroangiography, vol 1: Clinical Vascular Anatomy and Variations. 2nd Ed. Springer-Verlag, Berlin Heidelberg 2001.

17. Lotfi M, Nabavizadeh SA, Foroughi AA. Aortic arch vessel anomalies associated with persistent trigeminal artery. Clin Imaging. 2012; 36(3): 218-220, doi: 10.1016/j. clinimag.2011.08.018, indexed in Pubmed: 22542381.

18. Nekula J. [Carotid-vertebrobasilar anastomosis]. Cesk Radiol. 1989; 43(5): 339-343, indexed in Pubmed: 2632025.

19. Oszukowski P, Kaurzel Z. Koło tętnicze mózgu (Willisa) fenomen zespoleń tętnicznych- dobrodziejstwem natury. Acta Clin et Morphol (Przegląd Kopernikowski. 2001; 4(15): 12-15.

20. Padget $\mathrm{DH}$. The development of the cranial arteries in the human embryo. Contrib Embryol. 1948; 32: 205-261.

21. Raybaud C. Normal and abnormal embryology and development of the intracranial vascular system. Neurosurg Clin N Am. 2010; 21(3): 399-426, doi: 10.1016/j. nec.2010.03.011, indexed in Pubmed: 20561492.

22. Saltzman GF. Patent primitive trigeminal artery studied by cerebral angiography. Acta Radiol. 1959; 51(5): 329-336, indexed in Pubmed: 13649384.

23. Stoeter P, Marquardt B. Kombinierte Hirn- und Gefäßmißbildung bei einem dreijährigen Kind*: DandyWalker-Syndrom, Arteria primitiva trigemina und Hämangiom. ROFO Fortschr Geb Roentgenstr Nuklearmed. 1978; 128(06): 680-683, doi: 10.1055/s-0029-1230929.

24. Suzuki S, Morioka T, Matsushima T, et al. Moyamoya disease associated with persistent primitive trigeminal artery variant in identical twins. Surg Neurol. 1996; 45(3): 236-240, doi: 10.1016/0090-3019(95)00337-1.

25. Svehla F, Vítovec J. [Arteria primitiva trigemina as a possible cause of late epilepsy]. Cesk Radiol. 1972; 26(4): 175-178, indexed in Pubmed: 5040300.

26. Świątnicki W, Matusewicz M, Oszukowski P. Anatomicznofizjologiczne podstawy krążenia krwi w obrębie koła tętniczego mózgu (Willisa). Część druga: Rozwój tętnic podstawy mózgowia. Acta Clin et Morphol (Przegląd Kopernikowski). 2009; 12 (3-4): 18-20.

27. Takahashi M. Atlas of Vertebral Angiography. Urban \& Schwarzenberg. Munchen-Berlin-Wien Sgaku Shoin Ltd, Tokyo 1974. 